\title{
Where ethics is taught: an institutional epidemiology
}

\author{
Jonathan Beever ${ }^{1}(\mathbb{D}) \cdot$ Stephen M. Kuebler ${ }^{2} \cdot$ Jordan Collins $^{3}$ \\ Accepted: 5 February 2021 / Published online: 11 March 2021 \\ (C) The Author(s), under exclusive licence to Springer Nature Switzerland AG part of Springer Nature 2021
}

\begin{abstract}
The goal of this project is to argue for ethics as a necessary component of the institutional health. The authors offer an epidemiology of ethics for a large, metropolitan, very-high-research-activity (R1) university in the U.S. Where epidemiology of a pandemic looks at quantifiable data on infection and exposure rates, control, and broad implications for public health, an epidemiology of ethics looks to parallel data on those same themes. Their hypothesis is that knowing more about how undergraduates are exposed to ethics will help us understand to what extent they are infected with interest in ethics literacy, and potentially what immunity they develop against unethical and unprofessional conduct. These data also tell a story about the ethical health of institutions: to what extent its members are empowered to cultivate a culture of ethics and inoculated against ethical missteps. The authors argue that pro-ethics inoculation at research institutions is shaped by issues of complexity (space given to "hard" vs. "soft" skills within curricula), connotation (differences in meaning of "ethics" among and within disciplines), and collaboration (tensions between Ethics-Across-the-Curriculum and Ethics-In-the-Disciplines approaches to ethics). These issues make assessment of where ethics is taught all the more difficult. The methodology used in this project can readily be taken up by other institutions, with much to be learned from interinstitutional comparisons about the distribution of ethics across the curriculum and within the disciplines.
\end{abstract}

Keywords Ethics · Public health · Curriculum mapping - Ethical culture · Ethics across the curriculum $\cdot$ Ethics in the disciplines

Jonathan Beever

jonathan.beever@ucf.edu

Extended author information available on the last page of the article 


\section{Introduction and background}

The goal of this project is to argue for ethics as a necessary component of institutional health. The authors offer an epidemiology of ethics for a large, metropolitan, highresearch-activity university in the United States. Where epidemiology of a pandemic looks at quantifiable data on infection and exposure rates, control, and broad implications for public health, an epidemiology of ethics looks to parallel data on those same themes. Our hypothesis is that knowing more about how undergraduates are exposed to ethics will help us understand to what extent they are infected with interest in ethics literacy, and potentially what immunity they develop against unethical and unprofessional conduct. These data also tell a story about the ethical health of our institution: to what extent its members are empowered to cultivate a culture of ethics and inoculated against ethical missteps. ${ }^{1}$ Thus our goal is to make visible the landscape of ethics: where it is taught, within which units, and how that landscape has changed over time.

Emphasis on ethics continues to grow nationally. Engineering ethicist Michael Davis called this growth an "ethics boom" (1990), arguing that emphasis on ethics underwent several periods of rapid growth most recently since the 1980s (1990:168). This growth is increasingly reflected in professional codes of ethics, emphasis on ethics in education and training programs, and in professional accreditation structures like ABET. And to the extent that this growth was driven by ethics controversies in the past, its growth is stimulated even more so in the current moment with broad ethical questions of social media, election trolling, presidential tweets, pandemics, and social unrest.

Despite the amount of emphasis on ethics during the boom, the quality and consistency of that emphasis remains in question. Has ethics become more centralized or more dispersed within institutions? If we think of ethics education as a parallel to public health, the answer seems to be both: the normative place of ethics is more centralized than it used to be (that is, it continues to be seen as ethically good for institutions) and also the approaches to ethics education continue to diversify. Indeed, we have evidence that ethics and reasoning, like writing and communication, are important transferable skills (Hart 2015). Yet approaches like writing-across-thecurriculum (WAC) and writing-in-the-disciplines (WID) have become widely institutionalized as part of curricula of expertise, whereas parallel approaches to ethics have not.

Part of the reason for this may be the normativity of ethics itself. Seen (circularly) as a good thing, approaches to ethics have been taken up by disciplinary and institutional efforts without the guidance of technical ethics expertise. The ethics landscape at our institution, like most research institutions, reflects that diversity and includes ethical leadership programs, ethics in the disciplines, ethical literacy frameworks, professional ethics efforts, ethics and compliance intersections, and responsible conduct of research training, among others.

Given this complex landscape, the questions that drive our analysis here are not about the role of expertise (a question for later work), but about revealing institutional

\footnotetext{
${ }^{1}$ We think a culture of ethics is different and more important than an ethical culture. The latter is an evaluation of the extent to which members of an institutional culture each act ethically, whereas the former has to do with the extent to which members are actively engaged in the practice of developing ethics literacy.
} 
structure. We ask the following. Where is ethics taught at our institution? Has where ethics is taught changed over time? We recognize the vast existing literature on whether ethics can be taught, and the extent to which ethics should be taught, but see less scholarly emphasis on how and where ethics is taught.

We theorize three key reasons for this gap in the existing research on ethics education: complexity, connotation, and collaboration. First, this question about the placement of ethics is important for large research universities where centralized curricula (like great books programs, humanities core curriculum, et cetera) are made difficult by the diversity of college, programs, and professional foci. Universities are complex places, not only in terms of difference in organization, but also in difference in interdisciplinary spaces. Even within disciplines, ethics faces the problem of curricular space, particularly as disciplines become more and more specialized. In these contexts, ethics is often taught as part of a "soft skills" professionalization course which decreases its visibility and downplays its importance. The complexity of our institutions is a key problem for understanding where ethics is taught. Second, the term "ethics" connotes differently across disciplines and professions. While some ethical guidance or principles are common across contexts (e.g., "protect the public"), differences are prevalent. Does ethics include "broader impacts" of technical work? Does it focus on responsible conduct of research (RCR) issues like plagiarism? Does it connote safety in laboratory settings? Each connotation of its use makes tracking how and where ethics shows up more difficult. These distinctions become blurred as frontier work becomes increasingly interdisciplinary. How do students enculturate to ethics when they work across disciplinary boundaries, for which the connotations of ethics differ? Third, approaches to ethics education, generally, are collaborative and split between two different ethics-in-the-disciplines (EID) and ethics-across-the-curriculum (EAC). EID approaches emphasize teach-the-teachers peer education, with ethics specialists in one discipline helping non-specialists in another reach a level of comfort with teaching ethics within their own classes, labs, and programs. EAC approaches offer a complementary approach, emphasizing a well-researched strength in the dispersal of ethics education across a discipline's curricular plan. EID and EAC approaches to ethics education are well placed to answer this question of where ethics is taught, but they are more focused on pedagogical need than on institutional structure. The justification for EAC being that repeated engagement with ethical thinking builds habits of thought that preserve attention to ethics in an otherwise tight technical curriculum and makes for better professionals, richer integrity, and stronger institutional ethical cultures. These three driving concerns - complexity, connotation, and collaboration - are reflected in the small but diverse body of literature of projects looking at where ethics is taught.

The complexity of institutions, including their curricular density and the ways in which disciplines are divided up, continues to be a significant barrier to coherence and consistency of ethics education. Back in 1999, Karl Stephan reported an analysis of the curricula of engineering schools (UMass Amherst 2000). He concluded that only about one third of the nation's engineering schools require students to take any course in the ethics of engineering. Key among his findings is that fewer than $27 \%$ of schools require all students to take any ethics-related courses, and that only $10.2 \%$ of institutions surveyed require only a course that mentions ethics along with other topics (Stephan 1999; UMass Amherst 2000). In 2017, Walters, Heilbronn, and Daly looked at ethics 
education within teacher training in England. They found that ethics was not offered as a stand-alone course at any institution, but was embedded within the curriculum in a variety of ways. They found barriers to ethics education including student resistance, lack of time, the complex nature of the ways in which ethics education is provided within programs, and external demands placed upon institutions by professional organizations (393).

The connotation, or meaning of ethics, across disciplines and institutions is a second barrier framed by existing literature. Matchett argues that ethics at the undergraduate level is vital for moral judgment development (2008: 25), and yet we have failed to "devote sustained attention to precisely what ethical messages students are receiving and to how those messages are being conveyed" (25). This lack of coordination has important unintentional (bad) outcomes (27-8). This shortcoming has resulted in difficulty tracking where ethics is taught or even which courses include ethics content. Maxwell et al. (2015) completed a survey of ethics courses within initial teaching education curricula. In that project, they defined an 'ethics course' as "any course found, which, judging by the title and course description given in the university calendar, had as its primary content focus ethics, morality, or values in teaching" (2015). But, given the generosity of this definition and the diversity of connotation of ethics, they found that "borderline cases were not uncommon" (ibid).

In their analysis of where ethics is taught within teacher training in England, Walters et al. (2017) defined ethics education both in terms of codes of practice and specific professional standards and as a human practice concerned with relationships (2017: 387). This even broader definition allowed them to capture a wider variety of connotation of ethics. Yet, they learned that, despite existing impediments to the teaching of ethics at the institutions they studied, none of their respondents suggested a stand-alone core module or employing ethics specialists was a way forward (393). The diversity of approaches to and meanings of ethics across programs and institutions did not lead stakeholders to desire increased coherence or greater consistency.

Issues of collaboration also complicate analysis of where ethics is taught. David Haws' 2001 work on ethics in engineering education includes a section specifically titled "where is engineering ethics being taught?" (223-224). In that study of two thousand (2000) papers published as American Society of Engineering Education conference proceedings, Haws found that only forty-two (42) dealt with ethics. Thirty-two (32) of those identified the level of students involved. Of those, twentyfour (24) were focused on undergraduate students. Haws notes "in all of these [upper division undergraduate] offerings, ethics is only a small component of a larger course organized around other topics" (224). Haws does not address where these courses are offered, in terms of discipline or college, except to note that five of seven courses dedicated to issues of social issues were taught by non-engineers (224). Yet this analysis is suggestive of a broader national trend of relegating ethics content to the backseat of an existing course within a discipline rather than relying on available ethics expertise through interdisciplinary collaboration. Of course, that data is merely suggestive, since broader surveys of national trends here have not been completed. Existing studies of where ethics is taught, like the ones outlined above, have focused largely on discipline-specific course offerings. Common among their findings is a seeming reluctance to emphasize ethics within disciplines, due at least in part to the three problems of complexity, connotation, and collaboration we have outlined. 
Our project seeks to fill a gap in the literature by looking across disciplines at where ethics is taught. To extend the metaphor with which we started, our methodology follows the example set by existing literature and takes a public health and not a bioethics approach. That is, we are not looking at individual student experiences, and are not examining individual receptiveness to ethics, moral sensitivity, and other unique factors. Instead, we examine ethic at the community level, seeking to quantify the exposure level in term of number of courses emphasizing ethics, and where they are located across the institution by college and discipline.

The college model of our institution, the University of Central Florida (UCF), while certainly not unique, is one example of the diverse ways institutions of higher education are structured. UCF has a separate College of Optics, and a College of Arts and Humanities rather than a College of Arts and Sciences. UCF is one of the nation's largest institutions, with nearly sixty thousand undergraduate students enrolled and Carnegie classified as a very high research activity institution (UCF.edu 2020a). Yet UCF is also young, founded in 1963. Combined with its size, this means that UCF has faced explosive student growth and rapid restructuring leading to regular reconfiguration of programs and colleges. These particularities of institutional organization matter to our methodological approach to answering our research questions, and to how others might do the same at their own institutions.

\section{Methods}

\section{Data collection}

We examined undergraduate courses longitudinally over a ten-year period (2008-2018) and defined "ethics" courses as those that include a variant of "ethic" or "moral" in either their course title or course descriptions. We did not query at the level of course syllabi or course content due to limitations on access to that level of institutional data. We organized data by college, to get a sense of where ethics was taught in the context of our institutional structure. Our data reflect some of these particularities described below and in our data analysis. For instance, our institution's College of Undergraduate Studies and our Honors College are quantified alongside our other colleges despite offering very few of their "own" courses. Institutional particularities like these will need to be taken into account in the application of our methodology by other institutions.

Data collection focused on requests of existing institutional data. We first approached our institution's office of Institutional Knowledge Management (IKM) with a request for course descriptions and course titles from the past nine years that included "ethic*" or "moral*", where asterisk ("*") is the multi-character wildcard. The data returned were then compared against publicly available information in the course catalog from the same time period. Cross-examination revealed gaps in the IKM data: more courses meeting our criteria were listed in the historical catalogs than were returned from our institutional query. Based on our final compiled list of results, we made a second request of IKM for student credit hour ( $\mathrm{SCH}$ ) data from those courses. Calculations based on those two data sets form the basis of our final data set from which results were obtained. 
We made a similar data request to our distributed learning office for results from online course content, which could be used to search course documents and modules, and not just course titles and descriptions. However, staff were unable to offer these data, seeing "no clear path forward with our existing tools and practices" (Thompson correspondence). This limitation in access to available institutional data represents one limitation of our methodological approach, and therefore to our results. We next frame two other limitations to our approach to help better situate the results.

First, we cannot determine if ethics content appeared within a specific lecture, if ethicsrelevant topics like safety, integrity, or professional codes of ethics were embedded in other course content, or if students had paracurricular opportunities to engage ethics outside of the published curriculum. Take, for example, our College of Medicine and Biomedical Sciences $(\mathrm{COM})$. From an undergraduate perspective, it is not easy to find any undergraduate classes in COM that appear to be ethics promoting or focused. Some, like Stem Cell Biology, Human Genetics, Genetics I, Genetics II, and Embryology/Development seem like they would need to discuss ethics; yet none mention ethics in their descriptions. Looking at the degree requirements there is no evidence that the degree requires students to learn or engage in ethics. The degree program is stringent, with the most substantial possibility for variation in the seventeen credit hours of restricted electives, the only place ethics courses could be taken. However, the recommended plan of study includes two composition electives and no mention of ethics. Ethics may sneak in through paracurricular opportunities. The program description indicates that students are sent emails about extracurricular opportunities, especially seminars, which cover a wide variety of topics within the scope of the major, including potentially ethics. As a comparator, the College of Business Administration (BA) offers one clearly-marked ethics class ("Legal and Ethical Environment of Business") as part of the curriculum for accounting majors. Yet no other courses appear to be ethics-focused, based on their titles and course descriptions. From a student perspective, the degree program appears to be dense, facing the same problem of curricular space shared by many of its counterparts in STEM. The elective opportunities that do exist could include ethics-related courses from outside the program, but there is no requirement nor any indicated incentive that they should. Like COM, BA emails its students about extracurricular opportunities and seminars that they are hosting. These extracurricular activities and seminars can cover a variety of topics within the scope of the College's degree offerings. The emails that are sent occasionally have a primary or secondary focus of ethics, but speakers might touch on ethics within their discussion depending on the relevance to the focus of the discussion.

Second, our approach leaves out some courses. We have focused on our institution's undergraduate curriculum, which leaves out graduate courses (approximately 13\% of our 69,000 students are graduates students (UCF.edu 2020a, 2020b)). Our approach also leaves out variable courses in some departments and programs including capstones, independent studies, study abroad courses, and internship hours. Courses with diverse student-specific focus like these may have substantial ethics content that would not be captured in the generic catalog descriptions and titles. Of course, this same concern holds for most courses: descriptions give a generic sense of the content but not the faculty-specified direction in any particular semester.

In response to these perceived limitations to our approach, we emphasize explicit ethics content, and make note of the diverse ways in which implicit ethics content might show up within our institution's curricula. 


\section{Analysis}

To address the central research question - "Where is ethics taught?" - we posed four subsidiary questions.

1. What percentage of total courses in catalog are ethics courses?

2. What percentage of total courses actually offered are ethics courses?

3. What percentage of total courses listed in the catalog in a particular college are ethics courses?

4. Within a specific college, what percentage of courses actually offered are ethics courses?

To answer these questions, we organized information from the course catalogs and enrollment data from IKM into simple Excel spreadsheets (.xls format) and then wrote a Java project that analyzes the information (see Fig. 1). Spreadsheets were chosen for inputting data because this format is widely available to others who might want to implement the methods and Java project reported here. ${ }^{2}$

The script reads the data and saves it in a dynamically accessible database. The database is scanned and courses are flagged for which a match is found in either the title or description to search-terms entered by the user. For this work, the search terms were "moral*" or "ethic*" as noted above, but the script will accommodate other search terms. The script counts the number of courses which are listed versus those which are actually offered (earned student-credit hours). All courses are identified strictly by course-code, which is fixed by the Florida State University System, and not by the course title, which is subject to change. Totals are calculated by year and college for 1) number of courses in the catalog, 2) number of courses offered, 3) number of ethics courses in the catalog, and 4) number of ethics courses offered. The script outputs these totals by college and year in a simple spreadsheet. Totals generated by the script were verified by hand by evaluating data within the original spreadsheet. The search terms could catch unintended matches, if for example a "moral*" matched to a course title or description that includes the word "morale." Unintended matches were removed from the totals.

Although courses could have some mention of ethics that is not reflected in the title or description, those courses are not included under the assumption noted above that ethics cannot be a significant component of the course if it is not reflected in the title or description. To give one rudimentary example, our institution requires instructors to include an ethics and responsible-conduct statement ${ }^{3}$ in the syllabus for every course that admonishes students to avoid cheating, plagiarism, and other forms of student misconduct. Although this statement mentions ethics, it is clearly not an instructional focus, so it should not result in a course being counted in the present study.

\footnotetext{
2 The Java script is available for public use at https:/github.com/je-collins/WhereEthicsIsTaught. Researchers who use the code are requested to cite this work.

${ }^{3}$ See https://fctl.ucf.edu/teaching-resources/course-design/syllabus-statements/\#core.
} 


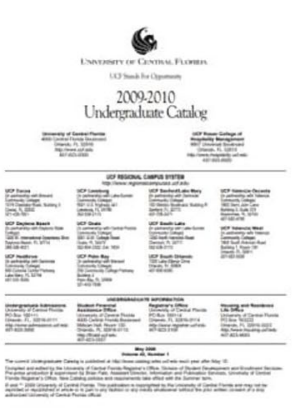

UCF undergraduate Catalogue

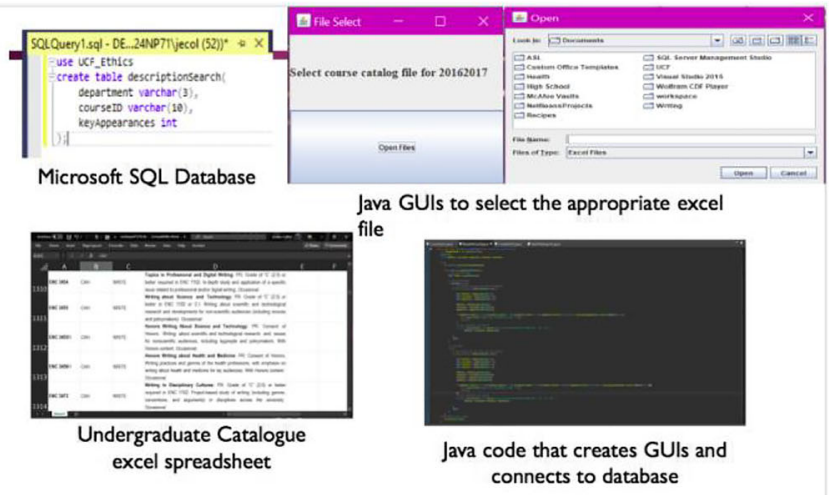

Fig. 1 Workflow development

\section{Results and discussion}

Table 1 summarizes institutional-level data by catalog year. The columns labelled "A" through " $\mathrm{D}$ " include the total number of courses in the catalog, the number of courses actually offered (generating student-credit hours, SCHs), and the number of each which are ethics courses as defined above. The corresponding values are provided as percentages in columns labelled "E" through " $\mathrm{H}$," and the third row explicitly states the ratio used to obtain the percentage listed. These data are also depicted graphically in Figs. 2, 3,4 and 5 , broken out by college and academic year.

The calculated percentages in Table 1 do not include courses taken for zero-credit, which are primarily internships, co-operative courses, or independent research experiences. Totals including zero-credit courses are indicated in parentheses in column B, in this and subsequent tables. Although zero-credit courses may be important vehicles for experiential learning often intended to cultivate professional ethics, their impact is implicit, through mentoring or professional engagement, rather than explicit, so they lie outside the scope of this study. One example of such a zero-credit course is a professional development course offered to graduate students in the Texts and Technology Ph.D. program. The course includes discussions of professional ethics, but it is not captured in our data set. Again, we argue that these courses can be ignored on the basis that the current study focuses on explicit rather than implicit training in ethics embedded within the curriculum. These data provide quantitative answers to our four secondary research questions, and the relative impacts of explicit and implicit experiences are discussed further below.

\section{What percentage of total courses in catalog are ethics courses?}

Table 1 shows that our institution's course catalog lists roughly 4000 undergraduate courses over the evaluation period. An average of 85.5 courses $(2 \%)$ had a significant ethics component. The number of ethics courses in the catalog was as high as 89 in $2010 / 11$, and as low as 83 in 2009/10 and 2012/13. Across the institution, ethics courses constituted between $1.80 \%$ and $2.29 \%$ of total credit-earning courses.

Another notable result is the perceived growth of offerings across colleges over time. The total courses listed in the catalog grew by only $0.4 \%$ over this nine-year window, despite 


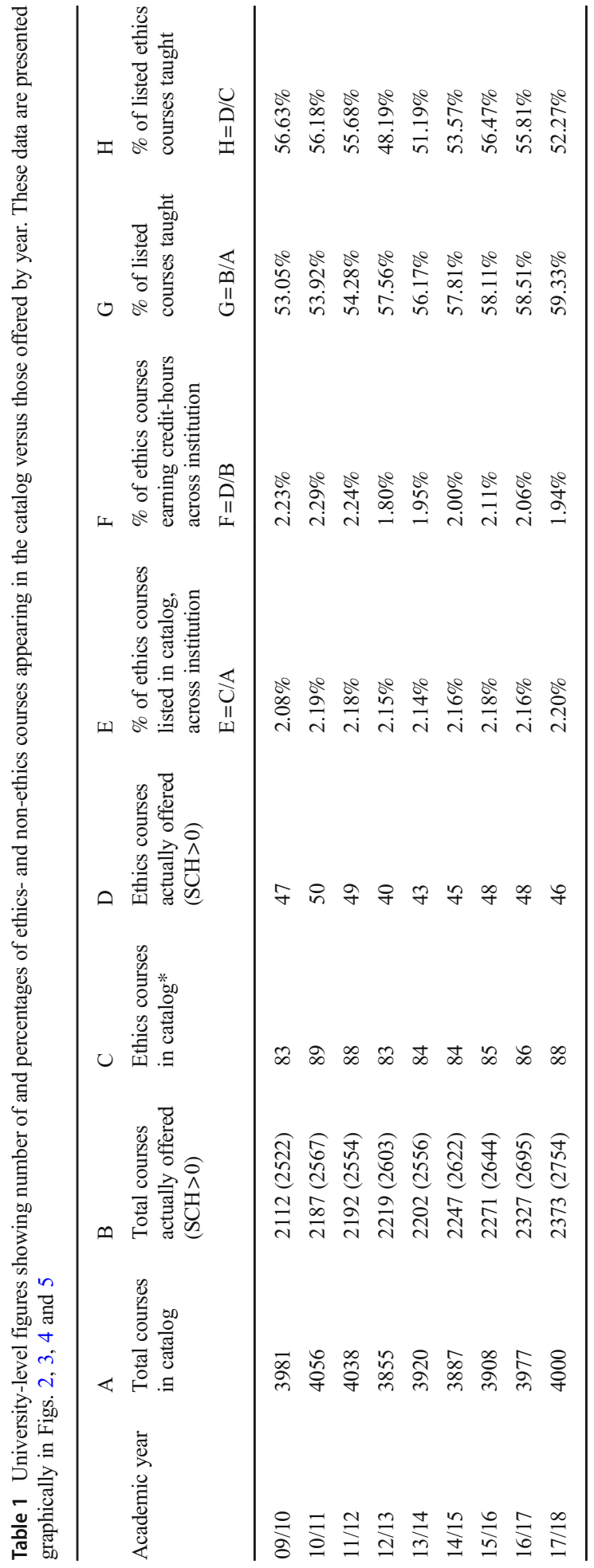




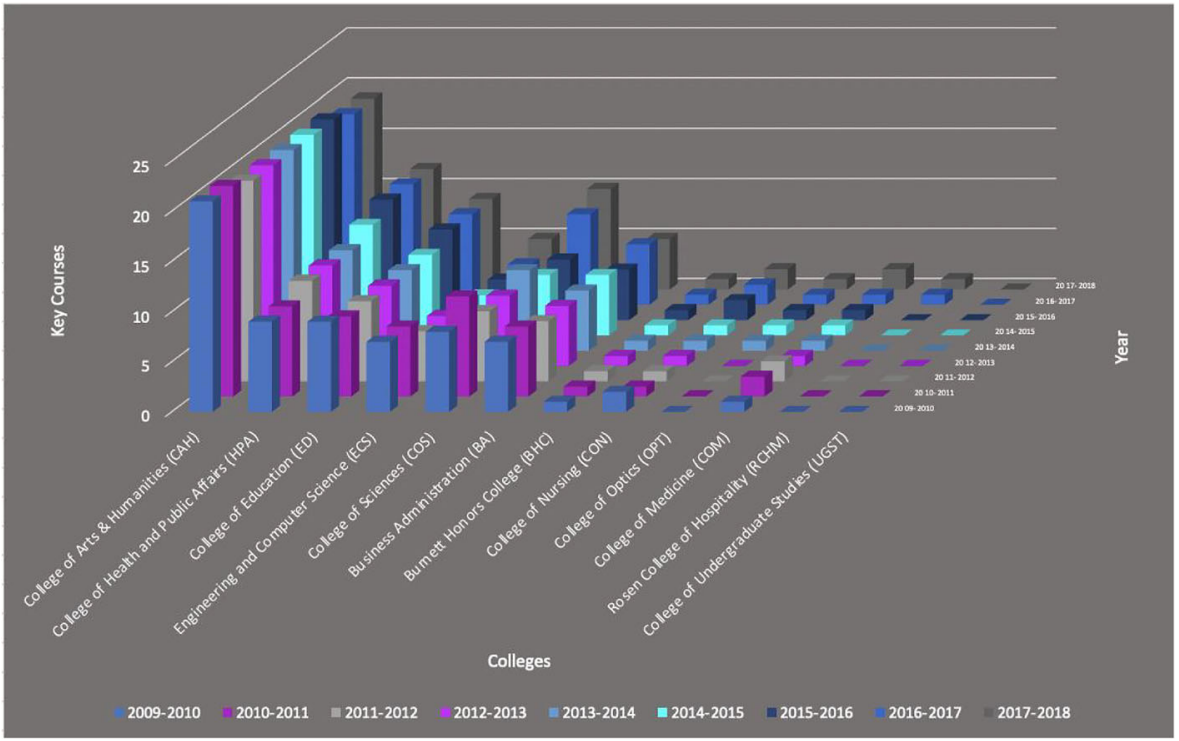

Fig. 2 Number of ethics courses listed in the catalog, grouped by college and year

enrollment growing by nearly $21.9 \%$ (from 53, 537 in 2009 to 68,571 in 2018) (UCF 2020). Like total course offerings, ethics course listings remained nearly static across this time period (see Fig. 2, and next section below). One can infer from these data points that course caps increased over this time period, adding more students per class as the institution grew. This is made visible in comparing Figs. 2 and 3 below, which visualize ethics courses listed in the catalog and ethics courses earning credit hours by year, respectively.

The implications here for institutional ethics are significant. Like other broad skilldevelopment disciplines, including writing, lower student caps in courses are important markers of success. The development of important skills in ethical decision-making, including ethical sensitivity (Weaver et al. 2008; Tuana 2014) and empathy (Hess et al. 2017), requires interpersonal dialogue and debate, which is facilitated more readily in smaller group discussions where students feel empowered to have a stronger voice. ${ }^{4}$ The ideal instructor-to-student ratio for ethics classes is an open question that remains to be examined empirically. However, tracking the ratio of ethics classes offered across disciplines and colleges alongside student growth provides one measure of the health of an institution's ethical culture.

\section{What percentage of total courses actually offered are ethics courses?}

Averaged across all years studied, $54.00 \%$ of ethics courses listed in the catalog were actually offered (Min. $=48.19 \%$ in 2012/13; Max. $=56.63 \%$ in 2009/10). In comparison, $56.51 \%$ of all courses listed in general were offered, on average (Min. $=53.05 \%$ in 2009/10; Max. $=59.32 \%$ in $2017 / 18$ ). So ethics courses were only about $2 \%$ less likely to be offered

\footnotetext{
${ }^{4}$ A 2017 meta-analysis of RCR education found discussion to be less effective than some other strategies including field-specific compliance training as instructional approaches to that narrow area of ethics (Mulhearn et al. 2017).
} 


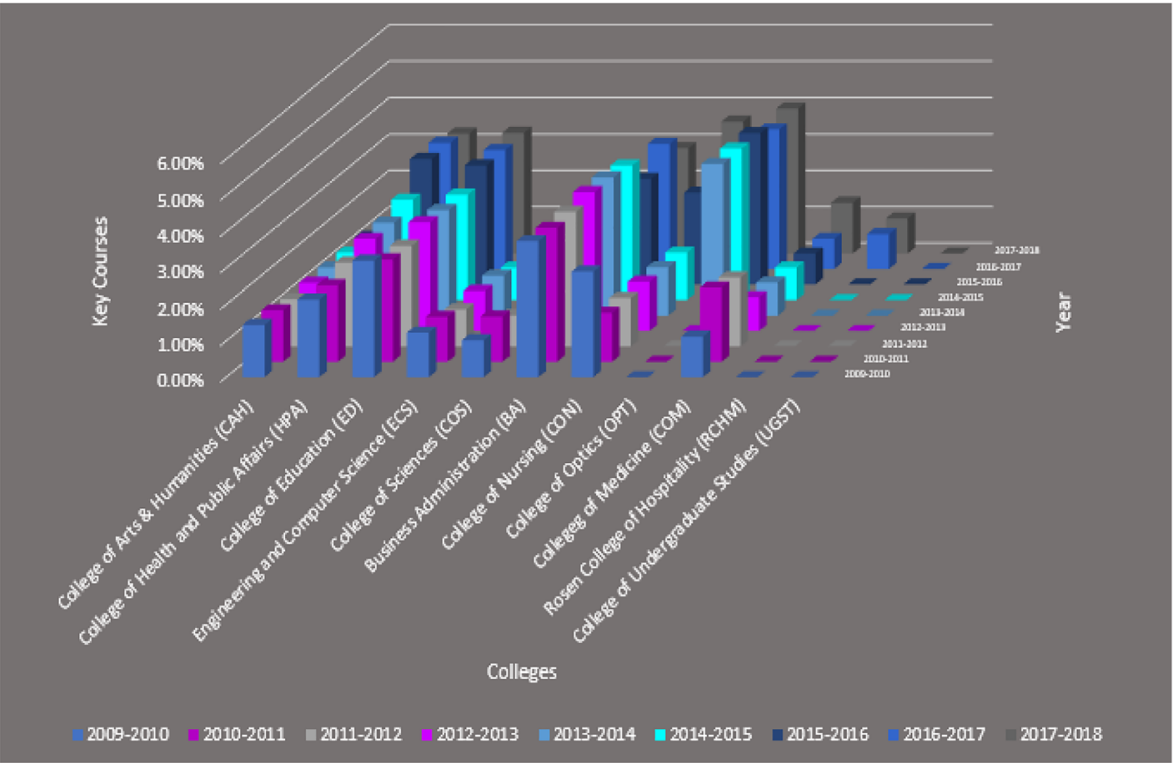

Fig. 3 Number of ethics courses earning student-credit hours, grouped by college and year

relative to the whole of course offerings. When the same comparison is made by academic year, there is no obvious correlation; for years in which fewer courses were offered overallperhaps due to changes in staffing across the institution - the percentage of ethics courses offered does not necessarily decrease. So overall, institutional-level changes do not appear to have driven identifiable changes in ethics-course offerings. Additionally, there is neither obvious increase nor decrease in the emphasis on ethics at the institutional level based on the availability or offering of ethics courses.

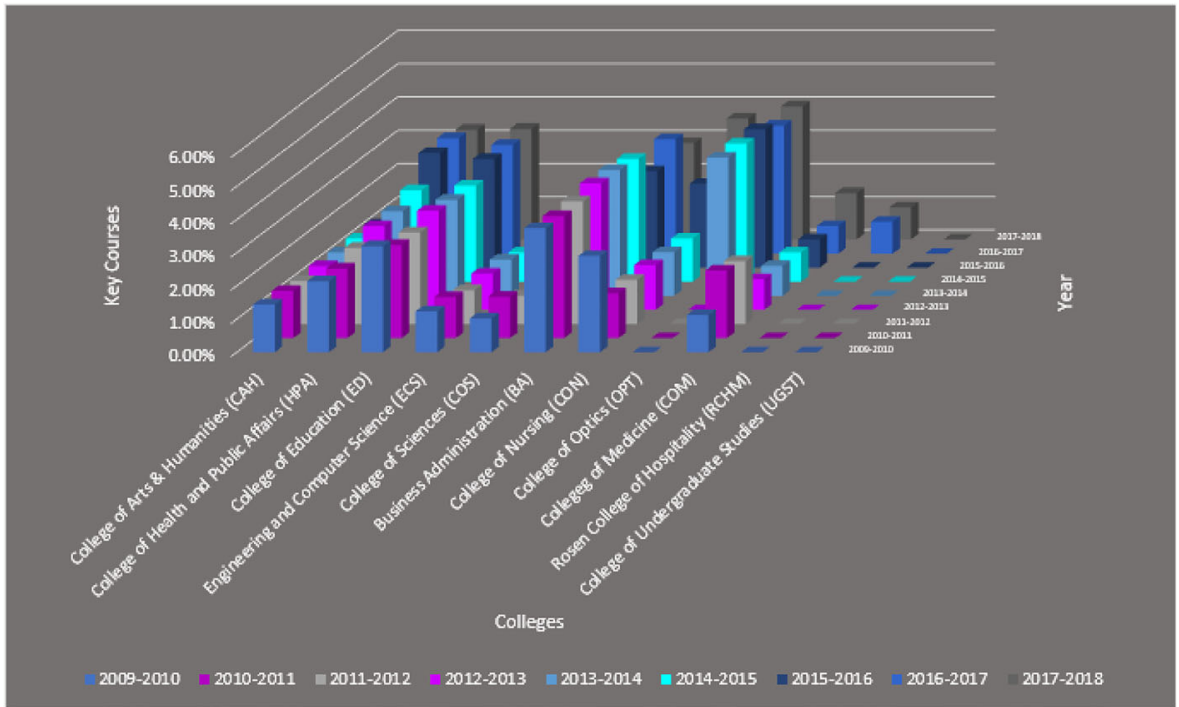

Fig. 4 Percentage of ethics courses listed in the catalog, grouped by college and year 


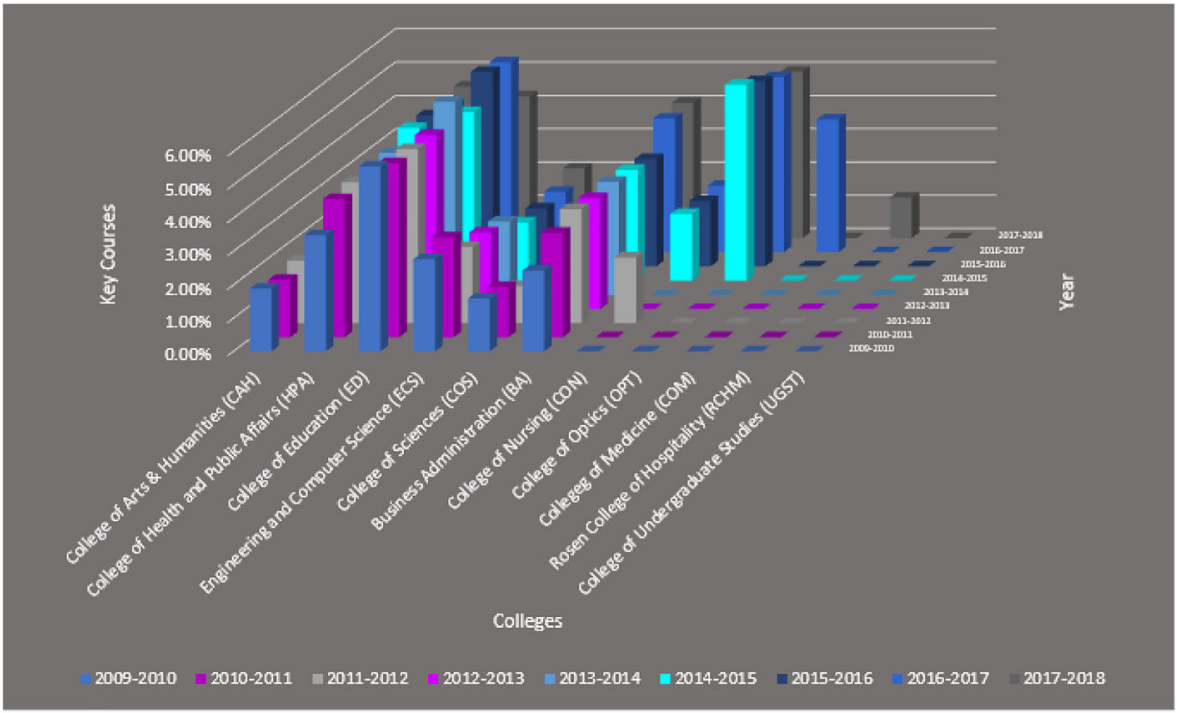

Fig. 5 Percentage of ethics courses earning student-credit hours, grouped by college and year

There was negligible change in the number of 1) courses listed in the catalog, 2) courses actually offered, and 3 ) ethics related courses. It is surprising that the number of ethics courses offered did not change significantly given influences during the same period, including the growth of the institution, the 2008 Great Recession, and increasing focus on ethics by professional organizations (Center 2020; Metcalf 2014), and federal agencies (US Office 2020; National Science Foundation 2020). Undergraduate enrollment at our institution grew by $25 \%$ (from 45,301 undergraduates in 2009/10 to 56,972 undergraduates in 2017/18), whereas total faculty members grew more slowly by $20 \%$ over the same period (from 1707 to 2051, (UCF 2020)). The increases in the number of students and faculty members did not result in any significant increase in courses teaching ethics.

The data indicate that ethics instruction is distributed unevenly across the institution, with Arts \& Humanities offering at least twice as many courses per year as the second nearest college. This result was expected, since ethics is at the heart of much of humanities discourse and normally seen as a secondary or "soft" skill in other domains. The next largest grouping of ethics courses is found with the College of Health and Public Affairs (HPA) and the College of Education (COE). This is followed closely by a third grouping consisting of BA, the College of Sciences (COS), and the College of Engineering and Computer Science (ECS). Only a small number of ethics courses are found in COM and the College of Nursing (CON).

\section{What percentage of total courses are actually offered in a particular academic year are ethics courses, and what percentage of total courses listed in the catalog in a particular college are ethics courses?}

In this section we discuss how we broke down institutional data by college and discuss the variations among and within colleges over time. We discuss data variants in colleges unique to our institution (Burnett Honors College, College of Optics and 
Photonics, and College of Undergraduate Studies) before moving to a comparison among three more standard colleges (e.g., Arts \& Humanities, and Sciences).

The importance of ethics within a college's curriculum can be assessed by calculating the "in-college percentage of ethics courses," defined as the percentage of ethics courses versus that college's total course offerings. Given that colleges vary tremendously in number of courses, associated disciplinary scope, number of departments, total enrollment, and so on, the in-college percentage of ethics courses also serves as an internally normalized metric for comparing the curricular emphasis on ethics between colleges.

As calculated, the in-college percentage of ethics courses is largest in the Burnett Honors College (BHC) (Table 2). Students in BHC complete degrees taking courses offered in their major departments and colleges, so BHC offers very few of its own courses, numbering between three (3) and six (6) within the evaluation period). All BHC students take a first-year experience course called "Freshman Symposium," which heavily emphasizes ethics, social justice, and academic integrity. The emphasis on ethics in the BHC program is genuine, but skewed as a percentage relative to other colleges because BHC offers so few of its own courses. Nonetheless, honors students are unique among incoming undergraduate cohorts at our institution in that they receive a heavy dose of ethics as freshmen (typically 500 per year) which sets a foundation for their undergraduate training and professional development.

Table 2 Course-data for the Burnett Honors College (BHC), by academic year

\begin{tabular}{|c|c|c|c|c|c|c|}
\hline $\begin{array}{l}\text { Academic } \\
\text { year }\end{array}$ & $\begin{array}{l}\text { Total } \\
\text { courses } \\
\text { in catalog }\end{array}$ & $\begin{array}{l}\text { Total courses } \\
\text { actually offered } \\
(\mathrm{SCH}>0)\end{array}$ & $\begin{array}{l}\text { Ethics } \\
\text { courses* } \\
\text { in } \\
\text { catalog }\end{array}$ & $\begin{array}{l}\text { Ethics courses } \\
\text { actually offered } \\
(\mathrm{SCH}>0)\end{array}$ & $\begin{array}{l}\% \text { of ethics } \\
\text { courses listed in } \\
\text { catalog across } \\
\text { college }\end{array}$ & $\begin{array}{l}\% \text { of ethics courses } \\
\text { in the catalog } \\
\text { earning credit-hours } \\
\text { across college }\end{array}$ \\
\hline $09 / 10$ & 4 & $3(5)^{\mathrm{a}}$ & 1 & 0 & $25.00 \%$ & $0.00 \%$ \\
\hline $10 / 11$ & 4 & $3(5)$ & 1 & 1 & $25.00 \%$ & $33.33 \%$ \\
\hline $11 / 12$ & 4 & $3(6)$ & 1 & 1 & $25.00 \%$ & $33.33 \%$ \\
\hline $12 / 13$ & 3 & $3(5)$ & 1 & 1 & $33.33 \%$ & $33.33 \%$ \\
\hline $13 / 14$ & 3 & $2(4)$ & 1 & 1 & $33.33 \%$ & $50.00 \%$ \\
\hline $14 / 15$ & 4 & $3(7)$ & 1 & 1 & $25.00 \%$ & $33.33 \%$ \\
\hline $15 / 16$ & 4 & $3(5)$ & 1 & 1 & $33.33 \%$ & $33.33 \%$ \\
\hline $16 / 17$ & 4 & $4(6)$ & 1 & 1 & $25.00 \%$ & $25.00 \%$ \\
\hline $17 / 18$ & 6 & $3(5)$ & 1 & 1 & $16.67 \%$ & $33.33 \%$ \\
\hline
\end{tabular}

a In each table below, numbers in parentheses in the "total courses actually offered" column are courses that are offered but not listed in the catalog. We cannot know if ethics is an explicit focus of those courses, since they have non-content-specific descriptions. These courses include independent study, study abroad, special topics, co-op internship study, civic engagement, and research undergrad research, among others. We chose to include them in the table as a sign-post for future research

*Most honors courses are "H" designations of courses in other colleges. For example, in 2017-2018 Burnett "owned" symposium (IDH 1920H), and 5 honors-in-the-major thesis and independent study courses 
To better compare the curricular emphasis on ethics between colleges, Figs. 4 and 5 show the in-college percentage of ethics courses plotted by college and by year, but excluding BHC because it does not house any majors. From these figures it is evident that the strongest emphasis on ethics is found in BA and the College of Education (ED). Interestingly, the total number of ethics courses in BA's catalog actually declined during the evaluation period, whereas the percentage of ethics courses offered actually increased.

If we exclude BHC for the moment and consider all other colleges, CREOL, The College of Optics and Photonics (OPT) overtakes all others in 2014 as having the highest percentage of ethics courses (Table 3). This unusual circumstance results from the unique situation of CREOL within The University of Central Florida and the field of optics. CREOL is an internationally recognized leader in research and education in optics, located at UCF (Murphy 2020; USNews 2020). As a flagship unit at UCF, CREOL became an independent college in 2004, which strengthened its existing MS and $\mathrm{PhD}$ program and positioned it to launch an ABET-accredited Bachelor of Science in Photonic Science and Engineering (BSPSE) in 2013. The BSPSE was structured to have ethics and responsible conduct embedded in the curriculum and explicitly taught in "Frontiers in Optics" (OSE 4930), a course created and taught annually by one of the present authors. OSE 4930 includes units on professional ethics, written and oral communication, use and critical reading of the literature, history and structure of the optics industry, professional networking, and concepts in intellectual property and entrepreneurship. Because CREOL focuses on a specific discipline, the number of courses it offers is small. Consequently, the addition of OSE 4930 increased the percentage of ethics courses offered by CREOL significantly, but disproportionately relative to other colleges. The prerequisites of the course are such that students can only take it in their junior or senior year. As such, it provides a foundation in ethics for professional development, but not on the front end of the early academic training.

Table 3 Course-data for CREOL, The College of Optics and Photonics (OPT), by academic year

College of Optics

\begin{tabular}{lllllll}
\hline $\begin{array}{l}\text { Academic } \\
\text { year }\end{array}$ & $\begin{array}{l}\text { Total } \\
\text { courses } \\
\text { in catalog }\end{array}$ & $\begin{array}{l}\text { Total courses } \\
\text { actually offered } \\
(\mathrm{SCH}>0)\end{array}$ & $\begin{array}{l}\text { Ethics } \\
\text { courses in } \\
\text { catalog }\end{array}$ & $\begin{array}{l}\text { Ethics courses } \\
\text { actually offered } \\
(\mathrm{SCH}>0)\end{array}$ & $\begin{array}{l}\% \text { of ethics } \\
\text { courses listed in } \\
\text { catalog across } \\
\text { college }\end{array}$ & $\begin{array}{l}\text { \% of ethics } \\
\text { courses in the } \\
\text { catalog earning } \\
\text { credit-hours across } \\
\text { college }\end{array}$ \\
\hline
\end{tabular}

\begin{tabular}{lllllll}
\hline $09 / 10$ & 7 & 1 & 0 & 0 & $0.00 \%$ & $0.00 \%$ \\
$10 / 11$ & 10 & 4 & 0 & 0 & $0.00 \%$ & $0.00 \%$ \\
$11 / 12$ & 10 & 1 & 0 & 0 & $0.00 \%$ & $0.00 \%$ \\
$12 / 13$ & 10 & 1 & 0 & 0 & $0.00 \%$ & $0.00 \%$ \\
$13 / 14$ & 24 & $6(7)$ & 1 & 0 & $4.17 \%$ & $0.00 \%$ \\
$14 / 15$ & 24 & $17(19)$ & 1 & 1 & $4.17 \%$ & $5.88 \%$ \\
$15 / 16$ & 24 & $18(21)$ & 1 & 1 & $4.17 \%$ & $5.56 \%$ \\
$16 / 17$ & 26 & $19(21)$ & 1 & 1 & $3.85 \%$ & $5.26 \%$ \\
$17 / 18$ & 25 & $20(21)$ & 1 & 1 & $4.00 \%$ & $5.00 \%$ \\
\hline
\end{tabular}


Table 4 Course-data for the College of Sciences (COS), by academic year

College of Sciences

\begin{tabular}{|c|c|c|c|c|c|c|}
\hline & $\mathrm{a}$ & $\mathrm{b}$ & $\mathrm{c}$ & d & $\mathrm{e}$ & $\mathrm{f}$ \\
\hline $\begin{array}{l}\text { Academic } \\
\text { year }\end{array}$ & $\begin{array}{l}\text { Total } \\
\text { courses in } \\
\text { catalog }\end{array}$ & $\begin{array}{l}\text { Total courses } \\
\text { actually offered } \\
(\mathrm{SCH}>0)\end{array}$ & $\begin{array}{l}\text { Ethics } \\
\text { courses } \\
\text { in catalog }\end{array}$ & $\begin{array}{l}\text { Ethics courses } \\
\text { actually } \\
\text { offered } \\
(\mathrm{SCH}>0)\end{array}$ & $\begin{array}{l}\% \text { of ethics } \\
\text { courses listed } \\
\text { in catalog } \\
\text { across college }\end{array}$ & $\begin{array}{l}\% \text { of ethics courses } \\
\text { in the catalog } \\
\text { earning credit- } \\
\text { hours across col- } \\
\text { lege }\end{array}$ \\
\hline $09 / 10$ & 788 & $440(537)$ & 8 & 7 & $1.02 \%$ & $1.59 \%$ \\
\hline $10 / 11$ & 802 & $460(556)$ & 10 & 7 & $1.25 \%$ & $1.52 \%$ \\
\hline $11 / 12$ & 810 & 447 (540) & 7 & 5 & $0.86 \%$ & $1.12 \%$ \\
\hline $12 / 13$ & 773 & $457(562)$ & 7 & 4 & $0.91 \%$ & $0.88 \%$ \\
\hline $13 / 14$ & 790 & $457(556)$ & 8 & 4 & $1.01 \%$ & $0.88 \%$ \\
\hline $14 / 15$ & 806 & $459(563)$ & 6 & 5 & $0.74 \%$ & $0.11 \%$ \\
\hline $15 / 16$ & 816 & $470(591)$ & 6 & 6 & $0.74 \%$ & $1.23 \%$ \\
\hline $16 / 17$ & 848 & $503(622)$ & 9 & 6 & $1.06 \%$ & $1.19 \%$ \\
\hline $17 / 18$ & 847 & $522(650)$ & 10 & 7 & $1.18 \%$ & $1.34 \%$ \\
\hline
\end{tabular}

Within the College of Sciences (COS), the number of ethics courses found in the catalog fluctuates across the study period between a low of six (6) and a high of ten (10) (Table 4). The number of ethics courses actually offered also fluctuated, decreasing from an initial peak of seven (7) courses offered, dipping to a low of four (4), and recovering to seven (7) across the study period. Although a catalog survey alone would suggest that COS is increasing its focus on ethics given an overall increase in total courses listed, a look at actual course offerings reveals no concomitant increase in teaching ethics.

Table 5 Course-data for the College of Engineering and Computer Science (ECS), by academic year

College of Engineering and Computer Science

\begin{tabular}{|c|c|c|c|c|c|c|}
\hline $\begin{array}{l}\text { Academic } \\
\text { year }\end{array}$ & $\begin{array}{l}\text { Total } \\
\text { courses } \\
\text { in catalog }\end{array}$ & $\begin{array}{l}\text { Total courses } \\
\text { actually offered } \\
(\mathrm{SCH}>0)\end{array}$ & $\begin{array}{l}\text { Ethics } \\
\text { courses } \\
\text { in catalog }\end{array}$ & $\begin{array}{l}\text { Ethics courses } \\
\text { actually offered } \\
(\mathrm{SCH}>0)\end{array}$ & $\begin{array}{l}\% \text { of ethics } \\
\text { courses listed } \\
\text { in catalog } \\
\text { across college }\end{array}$ & $\begin{array}{l}\% \text { of ethics courses } \\
\text { in the catalog } \\
\text { earning credit- } \\
\text { hours across col- } \\
\text { lege }\end{array}$ \\
\hline 09/10 & 568 & 254 (289) & 7 & 7 & $1.23 \%$ & $2.76 \%$ \\
\hline $10 / 11$ & 566 & $233(270)$ & 7 & 7 & $1.24 \%$ & $3.00 \%$ \\
\hline $11 / 12$ & 492 & $219(260)$ & 5 & 5 & $1.02 \%$ & $2.28 \%$ \\
\hline $12 / 13$ & 455 & $218(272)$ & 5 & 5 & $1.10 \%$ & $2.29 \%$ \\
\hline $13 / 14$ & 457 & $227(273)$ & 5 & 5 & $1.09 \%$ & $2.20 \%$ \\
\hline $14 / 15$ & 447 & $230(276)$ & 4 & 4 & $0.89 \%$ & $1.74 \%$ \\
\hline $15 / 16$ & 446 & $230(254)$ & 4 & 4 & $0.90 \%$ & $1.74 \%$ \\
\hline $16 / 17$ & 441 & $220(265)$ & 4 & 4 & $0.91 \%$ & $1.82 \%$ \\
\hline $17 / 18$ & 466 & $238(281)$ & 5 & 5 & $1.07 \%$ & $2.10 \%$ \\
\hline
\end{tabular}


Table 6 Course-data for the College of Medicine (COM), by academic year

College of Medicine

\begin{tabular}{|c|c|c|c|c|c|c|}
\hline $\begin{array}{l}\text { Academic } \\
\text { year }\end{array}$ & $\begin{array}{l}\text { Total courses } \\
\text { in catalog }\end{array}$ & $\begin{array}{l}\text { Total courses } \\
\text { actually offered } \\
(\mathrm{SCH}>0)\end{array}$ & $\begin{array}{l}\text { Ethics course } \\
\text { in catalog }\end{array}$ & $\begin{array}{l}\text { Ethics courses } \\
\text { actually offered } \\
(\mathrm{SCH}>0)\end{array}$ & $\begin{array}{l}\% \text { of ethics } \\
\text { courses listed } \\
\text { in catalog } \\
\text { across college }\end{array}$ & $\begin{array}{l}\% \text { of ethics } \\
\text { courses in the } \\
\text { catalog } \\
\text { earning credit- } \\
\text { hours across } \\
\text { college }\end{array}$ \\
\hline $09 / 10$ & 89 & $66(87)$ & 1 & 0 & $1.12 \%$ & $0.00 \%$ \\
\hline $10 / 11$ & 98 & 72 (91) & 2 & 0 & $2.04 \%$ & $0.00 \%$ \\
\hline $11 / 12$ & 106 & $76(98)$ & 2 & 0 & $1.89 \%$ & $0.00 \%$ \\
\hline $12 / 13$ & 108 & 83 (104) & 1 & 0 & $0.93 \%$ & $0.00 \%$ \\
\hline $13 / 14$ & 111 & 82 (105) & 1 & 0 & $0.90 \%$ & $0.00 \%$ \\
\hline $14 / 15$ & 112 & 88 (111) & 1 & 0 & $0.89 \%$ & $0.00 \%$ \\
\hline $15 / 16$ & 118 & 92 (112) & 1 & 0 & $0.85 \%$ & $0.00 \%$ \\
\hline $16 / 17$ & 121 & 25 (117) & 1 & 1 & $0.83 \%$ & $4.00 \%$ \\
\hline $17 / 18$ & 143 & 93 (122) & 2 & 0 & $1.40 \%$ & $0.00 \%$ \\
\hline
\end{tabular}

In the College of Engineering and Computer Science (ECS), ethics courses comprise about $1 \%$ of all course offerings, but as high as $2 \%$ of all courses actually offered (Table 5). The number of ethics courses in the catalog decreased over the study period, from a high of seven (7) to a low of four (4), then returning to five (5) ethics courses in 2017-2018. Based on course-offering, one might conclude that there is actually decreasing explicit emphasis of ethics in the engineering engineering curriculum, despite calls to increase training in ethics in STEM from national-level accreditation bodies like ABET (Milligan 2018). Yet it is noteworthy that each of the ethics courses was actually taught in each year. In this respect, ECS stands out. Roughly half of all courses in the ECS catalog was actually taught, which is common for large colleges at large public institutions. But because every ethics course on the books was actually taught, the percentage of ethics courses taught reaches roughly $2 \%$. So although changes in resources, staffing, and student interests may affect which courses are offered, the fact that all ethics courses available are actually taught implies that ethics is a priority in the ECS curriculum. Obviously much can be revealed by a deeper look at program content, non-curricular experience, and so on, but the comparison for ECS shows how care must be exercised in construing what role ethics or any other professional skill plays in a curriculum based on course offerings alone.

The College of Medicine was launched in 2009/10 with an inaugural class of 41 MD students, which rose to 479 by $2017 / 18$. Within that time, BS degrees were added in Biomedical Sciences, Biotechnology, and Medical Laboratory Sciences (MLS). Undergraduate courses in the catalog rose during that evaluation period from 89 to 143 (Table 6). The catalog shows one ethics course in most years, entitled "Principles of Biotechnology (BSC 2420)," and described as teaching "Principles, applications, laws, ethics and impact on society of biotechnology in agriculture, medicine, forestry, environment, computers/industrial/chemical engineering and business management." This course was only offered in 2016/17. A second course, entitled "Biotechnology and 
Table 7 Course-data for the College of Arts and Humanities (CAH), by academic year

College of Arts and Humanities

\begin{tabular}{lllllll}
\hline $\begin{array}{l}\text { Academic } \\
\text { year }\end{array}$ & $\begin{array}{l}\text { Total courses } \\
\text { in catalog }\end{array}$ & $\begin{array}{l}\text { Total courses } \\
\text { actually offered } \\
(\mathrm{SCH}>0)\end{array}$ & $\begin{array}{l}\text { Ethics } \\
\text { courses } \\
\text { in catalog }\end{array}$ & $\begin{array}{l}\text { Ethics courses } \\
\text { actually offered } \\
(\mathrm{SCH}>0)\end{array}$ & $\begin{array}{l}\text { \% of ethics } \\
\text { courses listed } \\
\text { in catalog } \\
\text { across college }\end{array}$ & $\begin{array}{l}\% \text { of ethics } \\
\text { courses in the } \\
\text { catalog earning } \\
\text { credit-hours } \\
\text { across college }\end{array}$ \\
\hline $09 / 10$ & 1457 & $739(872)$ & 21 & 14 & $1.44 \%$ & $1.89 \%$ \\
$10 / 11$ & 1483 & $808(906)$ & 21 & 14 & $1.42 \%$ & $1.73 \%$ \\
$11 / 12$ & 1540 & $854(936)$ & 20 & 16 & $1.30 \%$ & $1.87 \%$ \\
$12 / 13$ & 1510 & $868(948)$ & 20 & 9 & $1.32 \%$ & $1.04 \%$ \\
$13 / 14$ & 1532 & $849(915)$ & 20 & 12 & $1.31 \%$ & $1.41 \%$ \\
$14 / 15$ & 1538 & $864(936)$ & 20 & 12 & $1.30 \%$ & $1.39 \%$ \\
$15 / 16$ & 1525 & $870(941)$ & 20 & 13 & $1.31 \%$ & $1.49 \%$ \\
$16 / 17$ & 1552 & $866(936)$ & 19 & 11 & $1.22 \%$ & $1.27 \%$ \\
$17 / 18$ & 1535 & $883(948)$ & 19 & 9 & $1.24 \%$ & $1.02 \%$ \\
\hline
\end{tabular}

Genetic Engineering Seminar" (MCB 3522) appears in the catalog in three academic years, but it was never offered. COM stands out among UCF colleges as having one of the highest percentages for courses offered versus those in the catalog, averaging 94\%. Yet, at the undergraduate level, there are no ethics courses listed in the catalog.

The authors looked deeper into curriculum materials available to undergraduates, such as the curriculum handbook, mission statements, and program descriptions on the web. Ethics listed as one of several themes for professional focus in the handbook for the MLS program which reads: "...commitment to a strict code of ethics, observation of medical ethics related to patient results, and developing a standard of ethics." But as ethics does not appear in COM course descriptions or titles, it is difficult to understand how ethics is explicitly incorporated into professional development or how students would enculturate to ethics being a cornerstone for professional practice. Some students might choose to take Medical Ethics (PHI 5634) as an elective, but this course is offered through the philosophy department. PHI 5634 course is required for the MS degree in Biomedical Sciences, but is not listed as a required nor restricted elective for the BS. ${ }^{5}$

The College of Arts \& Humanities (CAH) listed between nineteen (19) and twentyone (21) ethics courses in the catalog, but those account for only between 1.44 and $1.24 \%$ of listed courses (Table 7). This percentage ranks CAH seventh among colleges in terms of listed ethics courses. Yet this ranking is somewhat misleading given the number of courses offered: $\mathrm{CAH}$ ranks first in the total number of courses listed in the catalog, and first in the number of ethics courses "on the books" (see Fig. 1). Given that

\footnotetext{
${ }^{5}$ BHC does reference we we see as implicit ethics engagement in only one of three program handbooks for students: in the MLS handbook, authors reference commitment to a strict code of ethics, observation of medical ethics related to patient results, and developing a standard of ethics (https://med.ucf.edu/biomed/files/ 2019/03/MLS-Handbook-Update-current_March_8_19.pdf).
} 
Table 8 Course-data for the College of Health and Public Affairs (HPA), by academic year

College of Health and Public Affairs

\begin{tabular}{lllllll}
\hline $\begin{array}{l}\text { Academic } \\
\text { year }\end{array}$ & $\begin{array}{l}\text { Total } \\
\text { courses } \\
\text { in catalog }\end{array}$ & $\begin{array}{l}\text { Total courses } \\
\text { actually offered } \\
(\mathrm{SCH}>0)\end{array}$ & $\begin{array}{l}\text { Ethics courses } \\
\text { in catalog }\end{array}$ & $\begin{array}{l}\text { Ethics courses } \\
\text { actually offered } \\
(\mathrm{SCH}>0)\end{array}$ & $\begin{array}{l}\text { \% of ethics } \\
\text { courses listed } \\
\text { in catalog } \\
\text { across college }\end{array}$ & $\begin{array}{l}\text { \% of ethics } \\
\text { courses in the } \\
\text { catalog earning } \\
\text { credit-hours } \\
\text { across college }\end{array}$ \\
\hline $09 / 10$ & 420 & $230(275)$ & 9 & 8 & $2.14 \%$ & $3.48 \%$ \\
$10 / 11$ & 429 & $217(257)$ & 9 & 9 & $2.10 \%$ & $4.15 \%$ \\
$11 / 12$ & 435 & $213(254)$ & 10 & 9 & $2.30 \%$ & $4.23 \%$ \\
$12 / 13$ & 396 & $213(249)$ & 10 & 9 & $2.53 \%$ & $4.23 \%$ \\
$13 / 14$ & 392 & $211(245)$ & 10 & 9 & $2.55 \%$ & $4.27 \%$ \\
$14 / 15$ & 399 & $218(256)$ & 11 & 10 & $2.76 \%$ & $4.59 \%$ \\
$15 / 16$ & 347 & $220(260)$ & 12 & 10 & $3.46 \%$ & $4.55 \%$ \\
$16 / 17$ & 345 & $225(260)$ & 12 & 10 & $3.48 \%$ & $4.44 \%$ \\
$17 / 18$ & 362 & $220(256)$ & 12 & 10 & $3.31 \%$ & $4.55 \%$ \\
\hline
\end{tabular}

philosophical ethics (both theoretical and applied) is housed here, as well as the focus of humanities disciplines generally on normative issues (e.g., social justice), the high number of ethics courses listed was expected.

Unexpected was the consistency of ethics courses listed in the catalog across the study period, as well as the overall drop in ethics courses actually offered. Given the tumultuousness of the period form 2009-2018, both in terms of social issues nationally and also in terms of institutional growth and change, we anticipated an increase in ethics offering in $\mathrm{CAH}$. The unexpected result points to, perhaps, stasis in curriculum

Table 9 Course-data for the College of Education (COE), by academic year

\begin{tabular}{lllllll}
\multicolumn{6}{l}{ College of Education } \\
\hline $\begin{array}{l}\text { Academic } \\
\text { year }\end{array}$ & $\begin{array}{l}\text { Total } \\
\text { courses } \\
\text { in } \\
\text { catalog }\end{array}$ & $\begin{array}{l}\text { Total } \\
\text { courses } \\
\text { actually } \\
\text { offered } \\
\text { (SCH>0) }\end{array}$ & $\begin{array}{l}\text { Ethics } \\
\text { courses } \\
\text { in }\end{array}$ & $\begin{array}{l}\text { Ethics courses } \\
\text { cattually } \\
\text { offered }\end{array}$ & $\begin{array}{l}\text { \% of ethics courses } \\
\text { listed in catalog } \\
\text { across college }\end{array}$ & $\begin{array}{l}\text { \% of ethics courses in the } \\
\text { catalog earning credit- } \\
\text { hours across college }\end{array}$ \\
\hline $09 / 10$ & 281 & $144(174)$ & 9 & 8 & $3.20 \%$ & $5.56 \%$ \\
$10 / 11$ & 285 & $153(187)$ & 8 & 8 & $2.81 \%$ & $5.23 \%$ \\
$11 / 12$ & 290 & $153(183)$ & 8 & 8 & $2.76 \%$ & $5.23 \%$ \\
$12 / 13$ & 268 & $153(183)$ & 8 & 8 & $2.99 \%$ & $5.23 \%$ \\
$13 / 14$ & 276 & $138(174)$ & 8 & 8 & $2.90 \%$ & $5.80 \%$ \\
$14 / 15$ & 276 & $138(181)$ & 8 & 7 & $2.90 \%$ & $5.07 \%$ \\
$15 / 16$ & 274 & $137(179)$ & 9 & 8 & $3.28 \%$ & $5.84 \%$ \\
$16 / 17$ & 274 & $140(176)$ & 9 & 8 & $3.28 \%$ & $5.71 \%$ \\
$17 / 18$ & 270 & $141(172)$ & 9 & 6 & $3.33 \%$ & $4.26 \%$ \\
\hline
\end{tabular}


Table 10 Course-data for the College of Business Administration (BA), by academic year

College of Business Administration

\begin{tabular}{lllllll}
\hline $\begin{array}{l}\text { Academic } \\
\text { year }\end{array}$ & $\begin{array}{l}\text { Total courses } \\
\text { in catalog }\end{array}$ & $\begin{array}{l}\text { Total courses } \\
\text { actually } \\
\text { offered } \\
(\mathrm{SCH}>0)\end{array}$ & $\begin{array}{l}\text { Ethics } \\
\text { courses } \\
\text { in } \\
\text { catalog }\end{array}$ & $\begin{array}{l}\text { Ethics courses } \\
\text { actually } \\
\text { offered } \\
0)\end{array}$ & $\begin{array}{l}\text { \% of ethics } \\
\text { courses listed } \\
\text { in catalog } \\
\text { across college }\end{array}$ & $\begin{array}{l}\text { \% of ethics courses } \\
\text { in the catalog } \\
\text { earning credit- } \\
\text { hours across col- } \\
\text { lege }\end{array}$ \\
\hline $09 / 10$ & 187 & $124(147)$ & 7 & 3 & $3.74 \%$ & $2.42 \%$ \\
$10 / 11$ & 190 & $128(156)$ & 7 & 4 & $3.68 \%$ & $3.13 \%$ \\
$11 / 12$ & 162 & $117(143)$ & 6 & 4 & $3.70 \%$ & $3.42 \%$ \\
$12 / 13$ & 157 & $120(148)$ & 6 & 4 & $3.82 \%$ & $3.33 \%$ \\
$13 / 14$ & 158 & $118(144)$ & 6 & 4 & $3.80 \%$ & $3.39 \%$ \\
$14 / 15$ & 162 & $120(139)$ & 6 & 4 & $3.70 \%$ & $3.33 \%$ \\
$15 / 16$ & 172 & $124(146)$ & 5 & 4 & $2.91 \%$ & $3.23 \%$ \\
$16 / 17$ & 174 & $124(147)$ & 6 & 5 & $3.45 \%$ & $4.03 \%$ \\
$17 / 18$ & 172 & $123(149)$ & 5 & 5 & $2.91 \%$ & $4.07 \%$ \\
\hline
\end{tabular}

modeling and revision within the College but also to a dispersion of ethics across disciplines: four other colleges at our institution took on at least one new ethics courses during our study period, for an overall gain in the number of ethics courses actually offered. Another possible reason for the drop is a national trend to shift away from liberal arts and emphasis on STEM education, coupled to the national push to integrate ethics into STEM fields.

Data for the College of Health and Public Affairs (HPA) and the College of Education (COE) are shown in Tables 8 and 9, respectively. HPA and COE stand

Table 11 Course-data for the College of Nursing (CON), by academic year

\begin{tabular}{lllllll}
\hline \multicolumn{6}{l}{ College of Nursing } & \multicolumn{6}{l}{} \\
\hline $\begin{array}{l}\text { Academic } \\
\text { year }\end{array}$ & $\begin{array}{l}\text { Total } \\
\text { courses } \\
\text { in } \\
\text { catalog }\end{array}$ & $\begin{array}{l}\text { Total courses } \\
\text { actually } \\
\text { offered } \\
(\mathrm{SCH}>0)\end{array}$ & $\begin{array}{l}\text { Ethics } \\
\text { courses } \\
\text { in } \\
\text { catalog }\end{array}$ & $\begin{array}{l}\text { Ethics courses } \\
\text { actually } \\
\text { offered } \\
\text { (SCH>0) }\end{array}$ & $\begin{array}{l}\text { \% of ethics } \\
\text { courses listed in } \\
\text { catalog across } \\
\text { college }\end{array}$ & $\begin{array}{l}\% \text { of ethics courses } \\
\text { in the catalog earning } \\
\text { credit-hours across } \\
\text { college }\end{array}$ \\
\hline $09 / 10$ & 69 & $46(48)$ & 2 & 0 & $2.90 \%$ & $0.00 \%$ \\
$10 / 11$ & 74 & $48(52)$ & 1 & 0 & $1.35 \%$ & $0.00 \%$ \\
$11 / 12$ & 75 & $51(53)$ & 1 & 1 & $1.33 \%$ & $1.96 \%$ \\
$12 / 13$ & 74 & $50(54)$ & 1 & 0 & $1.35 \%$ & $0.00 \%$ \\
$13 / 14$ & 76 & $51(54)$ & 1 & 0 & $1.32 \%$ & $0.00 \%$ \\
$14 / 15$ & 77 & $50(52)$ & 1 & 1 & $1.30 \%$ & $2.00 \%$ \\
$15 / 16$ & 79 & $51(53)$ & 2 & 1 & $2.53 \%$ & $1.96 \%$ \\
$16 / 17$ & 77 & $50(52)$ & 2 & 1 & $2.60 \%$ & $2.00 \%$ \\
$17 / 18$ & 55 & $50(52)$ & 2 & 1 & $3.64 \%$ & $2.00 \%$ \\
\hline
\end{tabular}


out among colleges as having among the highest percentage of ethics courses among their total offerings (Table 8). For HPA, the percentage of ethics courses offered increased from $2.14 \%$ to $3.31 \%$ of their total offerings over the study period. On average, the percentage of ethics courses offered is exceeded by the percentage of ethics courses actually earning student-credit hours, rising from $3.48 \%$ to $4.55 \%$ over the study period. This stands in marked contrast to most colleges for which the percentage of ethics courses earning credit is uniformly lower (Engineering being an exception). It is understandable that a large fraction of courses listed in a catalog may not actually be taught, due to staffing limitations, lack of enrollment, or a shift in curricular focus. But the fact that the fraction of ethics courses earning credit exceeds that listed in the catalog suggests that ethics instruction is filling a larger part of the curricular space in HPA than in many other colleges. Medical and public-health ethics is a well established sub-discipline of its own, and attention on health-ethics has grown, driven by challenges in health-care policy, privacy rights, access to health care, and the affordability of healthcare. So it is perhaps not surprising that ethics occupies a large and growing footprint in instruction in HPA. COE's ethics offerings generally increased, varying from $2.14 \%$ to $3.31 \%$ over the study period. Like HPA, COE also stands out as having a higher percentage of ethics courses among those actually earning student credit hours, reaching $5.84 \%$ in at least one year (Table 9).

Business Administration sits in a third tier in ethics-course offerings. A large fraction of BA courses include ethics instruction, fluctuating between $2.91 \%$ and $3.84 \%$ (Table $10)$. But given that the percentage of ethics courses actually offered is the same by year or lower, we would not conclude ethics has the same significance in the curricular space of BA as in HPA or COE. This is interesting given that ethical practices in business have been questioned, driven by events that have significantly impacted society, such as the banking collapse and economic downturn of 2008.

Table 12 Course-data for the Rosen College of Hospitality Management (RCHM), by academic year

Rosen College of Hospitality Management

\begin{tabular}{lllllll}
\hline $\begin{array}{l}\text { Academic } \\
\text { year }\end{array}$ & $\begin{array}{l}\text { Total courses } \\
\text { in catalog }\end{array}$ & $\begin{array}{l}\text { Total courses } \\
\text { actually } \\
\text { offered } \\
(\mathrm{SCH}>0)\end{array}$ & $\begin{array}{l}\text { Ethics courses } \\
\text { in catalog }\end{array}$ & $\begin{array}{l}\text { Ethics courses } \\
\text { actually } \\
\text { offered } \\
(\mathrm{SCH}>0)\end{array}$ & $\begin{array}{l}\% \text { of ethics } \\
\text { courses listed } \\
\text { in catalog } \\
\text { across college }\end{array}$ & $\begin{array}{l}\text { \% of ethics } \\
\text { courses in the } \\
\text { catalog } \\
\text { earning credit- } \\
\text { hours across } \\
\text { college }\end{array}$ \\
\hline $09 / 10$ & 82 & $74(87)$ & 0 & & & $0.00 \%$ \\
$10 / 11$ & 105 & $69(81)$ & 0 & 0 & $0.00 \%$ & $0.00 \%$ \\
$11 / 12$ & 102 & $65(78)$ & 0 & 0 & $0.00 \%$ & $0.00 \%$ \\
$12 / 13$ & 89 & $62(73)$ & 0 & 0 & $0.00 \%$ & $0.00 \%$ \\
$13 / 14$ & 90 & $64(74)$ & 0 & 0 & $0.00 \%$ & $0.00 \%$ \\
$14 / 15$ & 88 & $66(78)$ & 0 & 0 & $0.00 \%$ & $0.00 \%$ \\
$15 / 16$ & 88 & $66(75)$ & 0 & 0 & $0.00 \%$ & $0.00 \%$ \\
$16 / 17$ & 104 & $78(88)$ & 1 & 0 & $0.96 \%$ & $0.00 \%$ \\
$17 / 18$ & 103 & $82(92)$ & 1 & 1 & $0.97 \%$ & $1.22 \%$ \\
\hline
\end{tabular}


The colleges not discussed so far include the College of Nursing (CON) (Table 11), the Rosen College of Hospitality Management (RCHM) (Table 12), and the College of Undergraduate Studies (UGST) (Table 13). No ethics courses are found under UGST, whose offerings are limited to paracurricular opportunities such as interdisciplinary studies, co-operative opportunities, and study abroad. RCHM has a rich array of courses for students who seek careers in Central Florida's thriving tourism industry. But none list ethics strongly enough within the curricular focus to be identified under the methods employed in this work. Like COM, nursing could be expected to have a strong focus on medical ethics, but it is not reflected in course titles and description. Only one or two CON courses relate focus on ethics, potentially for reasons discussed below.

Here we summarize general findings and inferences we draw from our data. We find a slight growth in the total number of ethics courses listed in the catalog across our study period (from 83 to 88 , with a high of 89). This growth involved a modest spread of ethics across the disciplines, with colleges outside $\mathrm{CAH}$ beginning to offer ethics as part of their own curricular structures. The rate at which ethics infected into other disciplines is low, and it raises additional questions. The spread is not the result of a centralized ethics-in-the-disciplines (EID) campaign from philosophy or other seats of expertise. Instead, it appears as a holistic growth, perhaps driven by student and faculty interest and rapid institutional growth. Yet even this slow spread of ethics may in fact be asymptomatic because the number of ethics courses actually offered remained static across the study period (from 47 to 46 , with a high of 48). So although ethics courses are spreading across the curriculum, it is not necessarily equating to an infusion of ethics into student experience and institutional culture. Coursework continues to be the primary vehicle for explicit student training and as such it is among the most useful diagnostics for measuring students' exposure to ethics. The data suggest that students'

Table 13 Course-data for the College of Undergraduate Studies (UGST), by academic year

College of Undergraduate Studies

\begin{tabular}{lllllll}
\hline $\begin{array}{l}\text { Academic } \\
\text { year }\end{array}$ & $\begin{array}{l}\text { Total courses } \\
\text { in catalog }\end{array}$ & $\begin{array}{l}\text { Total courses } \\
\text { actually } \\
\text { offered }(\mathrm{SCH} \\
>0)\end{array}$ & $\begin{array}{l}\text { Ethics courses } \\
\text { in catalog }\end{array}$ & $\begin{array}{l}\text { Ethics courses } \\
\text { actually } \\
\text { offered } \\
(\mathrm{SCH}>0)\end{array}$ & $\begin{array}{l}\text { \% of ethics } \\
\text { courses listed } \\
\text { in catalog } \\
\text { across college }\end{array}$ & $\begin{array}{l}\text { courses in } \\
\text { the catalog } \\
\text { earning credit- } \\
\text { hours across } \\
\text { college }\end{array}$ \\
\end{tabular}

\begin{tabular}{lllllll}
\hline $09 / 10$ & 9 & $9(18)$ & 0 & 0 & $0.00 \%$ & $0.00 \%$ \\
$10 / 11$ & 10 & $11(21)$ & 0 & 0 & $0.00 \%$ & $0.00 \%$ \\
$11 / 12$ & 12 & $14(23)$ & 0 & 0 & $0.00 \%$ & $0.00 \%$ \\
$12 / 13$ & 11 & $13(19)$ & 0 & 0 & $0.00 \%$ & $0.00 \%$ \\
$13 / 14$ & 11 & $14(22)$ & 0 & 0 & $0.00 \%$ & $0.00 \%$ \\
$14 / 15$ & 11 & $15(25)$ & 0 & 0 & $0.00 \%$ & $0.00 \%$ \\
$15 / 16$ & 11 & $15(23)$ & 0 & 0 & $0.00 \%$ & $0.00 \%$ \\
$16 / 17$ & 11 & $13(21)$ & 0 & 0 & $0.00 \%$ & $0.00 \%$ \\
$17 / 18$ & 12 & $11(23)$ & 0 & 0 & $0.00 \%$ & $0.00 \%$ \\
\hline
\end{tabular}


enculturation to ethics cannot have grown impactfully through explicit training in coursework over the study period.

Second, we might infer that ethics does not play an important role at our institution, given the low percentage $(0 \%-4.6 \%)$ of ethics courses earning credit hours across colleges. Yet this might not be a strong inference, given that our methodology accounts only for courses with "ethics" or "moral" in the title or description. Not only might a range of other courses include a less explicit ethics emphasis or content, but also do a host of other trainings, modules, workshops, and extracurricular education efforts. General inferences about the overall breadth or strength of ethics education at our institution cannot be made from our data.

As an example, the College of Nursing (CON) shows merely a nominal increase in ethics courses offered (from zero to one) across our study period, despite nursing being one of the key colleges in which we would expect to see ethics given an explicit focus. Based on our data alone, we might conclude that $\mathrm{CON}$ focuses on technical content at the expense of ethics; yet, this inference is beyond that which our data can support. Rather, this disconnect between our hypothesis or institutional intuition about where ethics should be taught at a research university is more likely explainable by turning back to our distinction between explicit and implicit ethics. We find it more likely that ethics is so well integrated into the practices and professionalization of nursing that it is not called out by name and so it is not picked up by our methods. Our assessment is merely hypothetical: complementary data collection and analysis techniques are required to answer it empirically. But it does beg the question of how well students understand the foundational importance of ethics in their discipline when it is not explicitly visible within course work.

\section{Concluding perspectives}

Our initial hypothesis was that knowing more about the exposure rate of ethics among undergraduate students would inform to what extent they are infected with ethics. The epidemiological study we have conducted examines only undergraduate courses that explicitly called out "ethic" or "moral" in their titles and descriptions: a single measure of a complex public health issue. We argue that pro-ethics inoculation at research institutions was shaped by issues of complexity (space given to "hard" vs. "soft" skills within curricula), connotation (differences in meaning of "ethics" among and within disciplines), and collaboration (tensions between EAC and EID approaches to ethics). These issues make assessment of where ethics is taught all the more difficult.

We have leaned on the public health analogy to describe our approach to this problem of where ethics is taught for two reasons. First, the methodologies used in studying disease transmission and curriculum mapping are parallel, although of course their content differs. Second, we did so to articulate a deeper premise: namely, that ethics education is itself a public health issue. Values and their conflicts charge our social and political landscape, change ways we live and act in our environments, and shape the nature and future of our relationships. Building ethics literacy in our students - helping them more clearly identify, deeply engage with, and richly act on reasoned values - builds the sort of social, political, and personal engagement that continues to be the broad target of liberal education. 
We identify several next steps for future work on this topic. First, the methodology we outlined and used in this project can readily be taken up by other institutions, with much to be learned from inter-institutional comparisons about the distribution of ethics across the curriculum and within the disciplines. Second, this work gets at key conceptual distinctions between ethics-across-the-curriculum (EAC) efforts and ethics-in-the-disciplines (EID) efforts, which have not been sufficiently analyzed in the existing literature. For example, what relationship between EAC and EID approaches best supports ethics literacy development and satisfaction with ethics education among undergraduate students? Third, our approach does not get at individual student impacts, which could be done by collecting data on student credit hours and individual student enrollment. Our data cannot differentiate between individual students and student populations generally. For example, to what extent does a single student with high ethics interest impact data results by taking multiple ethics courses across disciplines?

As a final note, this project was designed and developed during both a public health pandemic, in the form of COVID-19, and also a period of deep social and political unrest. If ethics is taught widely if not deeply across disciplines, as our data suggests, what conditions would change the makeup or impact of this landscape? What external challenges to ethics inoculation exist and what roles do that play? These broader concerns shape the future of institutional ethics cultures: the broader public health of ethics.

Code availability (software application or custom code) code used in analysis will be available by online repository as cited in this publication.

Authors' contributions Collins' primary responsibility was data handling and processing, including development of the code used for analysis, and creation of data graphs and charts. Kuebler and Beever led project design and development, article writing, and analysis of data.

Funding This material is based partly upon work supported by the National Science Foundation under Grant No. 1711356 and Grant No. 2024296.

Data availability data used in this analysis will be available as a supplemental document to this publication.

\section{Declarations}

Conflict of interest The authors have no conflicts of competing interests to report.

\section{References}

Center for the Study of Ethics in the Professions. 2020. The Ethics Code Collection. http:// ethicscodescollection.org. Accessed 10 July 2020.

Davis, Michael. 1990. The ethics boom: What and why. The Centennial Review 34 (2): 163-186.

Hart Research Associates on Behalf of the Association of American. 2015. "Falling Short? College Learning and Career Success. Association of American Colleges \& Universities.” https:/www.aacu.org/leap/ public-opinion-research/2015-survey-results. Accessed 29 Dec 2020.

Haws, David. 2001. Ethics instruction in engineering education: A (mini) meta-analysis. Journal of Engineering Education 90 (2): 223-229. 
Hess, Justin L., Jonathan Beever, Johannes Strobel, and Andrew O. Brightman. 2017. Empathic PerspectiveTaking and Ethical Decision-Making in Engineering Ethics Education. In Philosophy and Engineering. Philosophy of Engineering and Technology, ed. D. Michelfelder, B. Newberry, and Q. Zhu, vol. 26. Cham: Springer. https://doi.org/10.1007/978-3-319-45193-0_13.

Matchett, Nancy J. 2008. Ethics across the curriculum. New Directions for Higher Education 142: 25-38.

Maxwell, Bruce, Audrée Tremblay-Laprise, and Marianne Filion. 2015. A survey of ethics curriculum in Canadian initial teacher education. McGill Journal of Education 50, 1 (1) https://mje.mcgill.ca/article/ view/9205/7043. Accessed 8 Jul 2020.

Metcalf, Jacob. Nov 9, 2014. Ethics Codes: History, Context, and Challenges. https://bdes.datasociety.net/ council-output/ethics-codes-history-context-and-challenges/. Accessed 8 Jul 2020.

Milligan, Michael. 2018. "Technology and the Ethics Gap." https://www.abet.org/technology-and-the-ethicsgap/. Accessed 10 July 2020.

Mulhearn, Tyler J., Logan M. Steele, Logan L. Watts, Kelsey E. Medeiros, Michael D. Mumford, and Shane Connelly. 2017. Review of instructional approaches in ethics education. Science and Engineering Ethics 23: 883-912.

Murphy, Justine. 2020. Optics, Photonics Programs are Lighting the Way. Photonics Media. https://www.photonics. com/Articles/Optics_Photonics_Programs_Are_Lighting the_Way/a57686. Accessed 8 July 2020.

National Science Foundation. 2020. "Ethical and Responsible Research." https://www.nsf.gov/pubs/2019/ nsf19609/nsf19609.htm. Accessed 8 July 2020.

Stephan, Karl. 1999. A survey of ethics-related instruction in U.S. engineering programs. Journal of Engineering Education 88 (4): 459-464.

Tuana, Nancy. 2014. An ethical leadership developmental framework. In: The Handbook of Ethical Educational Leadership. ed Branson, C.M., Gross, S.J., 153-175.

UCF.edu. 2020a. UCF Facts 2020-2021. https://ucf.edu/about-ucf/facts. Accessed 12 December 2020.

UCF.edu. 2020b. Story of the Decade: Quality Growth. UCFToday. https://www.ucf.edu/news/no-2-ucf/ story-of-the-decade-is/. Accessed 10 July 2020.

UMassAmherst. 2000. Most engineering schools do not require a course in ethics, UMass Amherst professor finds. UmassAmherst. https:/www.umass.edu/newsoffice/article/most-engineering-schools-do-notrequire-course-ethics-umass-amherst-professor-finds. Accessed 8 Jul 2020.

US News and World Report. 2020. Best atomic - molecular physics programs - US new rankings. US News and World Report. https:/www.usnews.com/best-graduate-schools/top-science-schools/atomic-sciencerankings. Accessed 10 July 2020.

US Office of Government Ethics. 2020. "Our History." https:/www.oge.gov/web/oge.nsf/about_our-history. Accessed 8 July 2020.

Walters, Sue, Ruth Heilbronn, and Caroline Daly. 2017. Ethics education in initial teacher education: Preservice provision in England. Professional Development in Education 44 (3): 385-396. https://doi.org/10. 1080/19415257.2017.1318773.

Weaver, Kathryn, Janice Morse, and Carl Mitcham. 2008. Ethical sensitivity in professional practice: Concept analysis. Journal of Advancements in Nursing 62 (5): 607-618.

Publisher's note Springer Nature remains neutral with regard to jurisdictional claims in published maps and institutional affiliations.

\section{Affiliations}

\section{Jonathan Beever ${ }^{1} \cdot$ Stephen M. Kuebler ${ }^{2} \cdot$ Jordan Collins $^{3}$}

1 Department of Philosophy, Texts \& Technology Ph.D. Program, College of Arts \& Humanities, UCF Center for Ethics, University of Central Florida, Orlando, FL 32816, USA

2 Department of Chemistry, CREOL, College of Optics and Photonics, Material Science and Engineering, University of Central Florida, Orlando, FL 32816, USA

3 Computer Science Department, College of Engineering and Computer Science, University of Central Florida, Orlando, FL 32816, USA 